\title{
The West-East Jade Transmission and the Formation of Chinese Civilization*
}

\author{
Ye Shuxian \\ School of Humanities, Shanghai Jiao Tong University, Shanghai 200240, China
}

\begin{abstract}
The major program of Chinese Academy of Social Sciences completed in 2012, entitled "The Research on Myths and Legends about Chinese Civilization Source”, led to such a conclusion: The imaginative myths and legends generated along with the Chinese civilization has a profound prehistoric root, far beyond the limit of the Chinese character generation period. The main path of Chinese myths and legends lies in the jade mythology and resulting jade belief. When viewing the origin of jade from a perspective of mythology, we find each major jade (e.g., jade ring, jade arc) form is covertly driven by a mythological concept. The investigation of the era and regional distribution of unearthed jade wares may outline the spreading path map of the jade mythology and belief.
\end{abstract}

Keywords: West-East Jade Transmission, Chinese civilization, jade culture

\section{Three Spreading Directions of Prehistoric Jade Culture}

From the perspective of the big tradition, around 8,000 to 4,000 years ago, the main directional movements of jade culture can be simply summarized into two patterns: North-South Jade Transmission and West-East Jade Transmission. The jade production originated from the Xiliao River Basin in the North began with the Xinglongwa culture, with the jade ring as the first dominant jade form. The jade culture made debut in the eastern part of Inner Mongolia some 8,000 years ago, gradually spread to the east and south, and arrived at northern Hebei province and the Japanese archipelago hundreds of years later. This is evidenced by the jade unearthed from the Beifudi site of Yi County, which is about 7,500 years old. The early jade culture in the north further spread southward, reaching the coastal area of Zhejiang about 7,000 years ago, as evidenced by the jade ring unearthed from Yuyao Hemudu culture site. After the slow spread over 2,000 years, the variety of jade articles gradually increased. The prehistoric jade culture production culminated in the Lingjiatan culture and the Liangzhu culture about 5,000 years ago. The distribution of prehistoric jade culture almost reached the most of the eastern China regions. It arrived in the Lingnan area about 4,000 years ago, and even in Taiwan, Hong Kong and Vietnam. The spectacular history of the North-South Jade Transmission lasted for a period of 4,000 years. Before the beginning of the history of Chinese civilization, the jade mythology underlay the ideological concept of the East Asian unified regime, and laid the cornerstone of cultural identity for the ensuing Xia, Shang and Zhou dynasties.

Compared with the long journey of the North-South Jade Transmission, the cultural communication

\footnotetext{
* Fund program: This article was funded by the program of Shanghai Jiao Tong University titled "World-class Universities and First-class Subjects", and the program of Shanghai City titled "Shanghai Social Science Research and Innovation Base: Chinese Creation Myth Studies” (2017WSH002).

Author: Ye Shuxian (1954-), senior professor of Shanghai Jiao Tong University
} 
process of the East-West Jade Transmission appeared a little later and took a shorter time. It started from about 6,000 years ago and ended 4,000 years ago, lasting more than 2,000 years. This made the jade mythology and its driven jade production, which used to be popular in the eastern coastal areas, gradually enter the Central China region, forming a system of jade rituals in the Longshan culture period. The most outstanding examples are the Shijiahe culture in Hubei 4,300 years ago and the Tao Temple site in southern Shanxi 4,500 years ago. Through the radiating influence of the Central Plains, it spread from the central region to the western and northwestern regions, and reached the Hexi Corridor. The Qijia culture jade ritual system 4,000 years ago was at a glorious period. So far, the spreading process of the jade culture, from triviality to extensiveness, had been completed. The core values of material and spiritual interaction had been prepared in advance for the birth of the Chinese civilization, and the jade mythology had permeated various expressions of Chinese characters since ancient times. Among them, it has become the most important cultural heritage of the Chinese people. Northwest Normal University has taken charge of a journal called The Silk Road for 20 years and it expects a more promising prospect.

When seeing the unearthed big jade cylinder (Jade Cong) in the Jinsha Site in the Chengdu Plain which is no different from the jade cylinder of the Liangzhu culture in the Taihu Lake Valley, people may feel puzzled: how did it make it to thousands of miles been away? This is no surprise when we view it from the development of West-East Jade Transmission. After experiencing the two major directional movements of prehistoric jade culture, what comes along the origin of the Central Plains civilization is another long-distance movement of jade raw materials in another direction-West-East Jade Transmission. The reason is that the spread of prehistoric jade culture is mainly the spread of jade and its mythology. Wherever the concept of jade as god went, it would drive the group behavior of jade production and consumption, making the jade a symbol of the local regime. However, the raw materials used to process jade articles were generally customized to local conditions, and there was no large-scale transportation of jade materials over long distances and across regions. However, with the rise of Xia, Shang and Zhou dynasties, there came the phenomenon of long-distance transportation of new jade material type, that is, the high-quality Hetian jade material produced in the Kunlun Mountains of Xinjiang, which premiered the large-scale transportation process to the Central Plains. This process had since continued for a period of 4,000 years. Till today, the solo show of the West-East Jade Transmission goes on. The only protagonist of the show is Hetian jade; the only place of origin is the Kunlun Mountains on the southern edge of the Tarim Basin. The direction of jade transmission is only way from west to east, supplying to the rulers of the Central Plains and the upper class.

\section{The Big Tradition of Jade Era and the Small Tradition of Chinese Characters}

The establishment of a civilization requires cross-regional supply of multiple strategic materials. The cultural history of West-East Jade Transmission is different from today's West-East Gas Transmission, because Hetian jade brings not only material but also spiritual power to the Chinese tradition, i.e., the prevailing core values of the country. This is the fundamental reason why today's West-East Gas Transmission cannot rival the ancient West-East Jade Transmission. From the fine jade articles unearthed from the Erlitou site in the tombs of the late Xia, Yin and Shang dynasties, it has been seen that there were batches of Hetian jade supply. The high-grade tombs of the Western Zhou Dynasty, such as the tomb of the Sanmenxia Guoguo tomb and the Shanxi Quwo Tomb of Emperor Jin, have a large number of jade artifacts that are exquisitely crafted and almost fully made of Hetian jade. Confucian followers after the Eastern Zhou Dynasty could admire the 
personality that "the gentleman is as warm as jade". The Taoist saint Laozi could advertise in Tao Te Ching the introversive spirit that "the saints are clad in brown and jade". Moreover, the history books record the stories of Bianhe Giving Jade Pu as a Gift and the Priceless Heshibi Jade. The concept of "turning disputes into jade and brocade" is therefore undisputedly upgraded to the highest value of this civilized country. It is because Hetian jade had entered the Central Plains and maintained the character of imperial jade that it inevitably surpassed and overwhelmed the performance of jade types in all other places. In the era of Emperor Wu of the Han Dynasty, the so-called opening of the Western Regions route was actually a re-confirmation of the West-East Jade Transmission route (which had been opened for 2,000 years) by official setting up some checkpoints and passes.

The "Silk Road", which was named by Lichhofen in 1877, a representative of the colonizing powers who came to China for mine investigation and exploration after the Opium War, was the terminology made by a typical European when being completely ignorant of the existence of the jade road. For this wishful terminology by the European, its legality had not been verified by the local Chinese. But it transformed into the "common sense" imposed by the tide of Western knowledge dissemination. Today, how to penetrate the cover of the "Silk Road" under the small tradition and explore the traditional truth of the jade road has become a pressing matter facing Chinese native scholars in the post-colonial era. The results of his study will be able to lead the country out of the plausible knowledge for more than a century, and carefully examine the materialistic and spiritual conditions that make China a multi-million-square-kilometer East Asian country.

The big tradition refers to the cultural relics unearthed before and beyond the written record, while the small tradition refers to the tradition of writing. The big tradition is related to the small tradition in such a way as nurturing and spawning, being nurtured and being spawn; the small tradition is related to the big tradition in such a way as substitution and obscuration. The latter small tradition relies on text symbols, which obscures the big tradition like this: $\mathrm{R}$ the words into common sense and mask the earlier prototype code. Today's scholars need to learn the way to mask, that is, to explore and interpret the prototype code. For example, the ancient Chinese goddess Nvwa made stone to patch the sky, a mythical story told by the small tradition. From Huainanzi to Dream of Red Mansions, the mythical plots familiar to later generations obscured the source of the belief in the concept of making stones for the sky. The pre-historic ancestors imagined the body of the sky as being made of jade. As a result, jade not only represents the gods, but also represents all good values and the eternal life. Just ask what is the five-color stone that Nvwa made for the sky? It is not difficult to see whatever has the name of stone is good jade. How to prove? Please see the following paragraph of The Classic of Mountains and Seas: West Mountains:

(In Mishan) The Danshui River flows out of this mountain and runs to the west before it empties itself into the Jize Marsh. In the river there is a great deal of white jade. Jade grease gushes up from its source and churns around. Emperor Huangdi ate this jade grease and used it as a ritual offering. Jade grease creates dark jade. The jade grease that gushes up is used to irrigate the cinnabar trees. In five years, the cinnabar tree turns into the tree of five bright colors and five fragrant flavors. Then Emperor Huangdi took some lustrous jade flowers from Mount Mishan and threw them on the southern slope of Mount Zhongshan (Guo Pu annotated that this is the seed of all jades). The superb gemstones are exquisite. They are firm and the veins of color are fine and delicate. They are also thick and glossy, shining brightly with five colors shooting out to couple hardness with softness. The ghosts and spirits of the sky and the earth eat this jade and accept it as a ritual offering. The gentleman wears it to guard against misfortune. 
Mishan, as part of the Kunlun Mountains in the west, produces a special jade called "superb gemstone" by ancient people. In addition to firmness and delicateness, it is visually "shining brightly with five colors". So the material Nvwa used for patching the sky is the jade stone that is holy and eternal. The judgment that "the superb gemstones are exquisite" suggests the reason why it serves as the food of ghosts and spirits of the sky and the earth, as well as the reason why gentlemen must wear a gemstone in rituals and ceremonies.

\section{West-East Jade Transmission and the Chinese Civilization}

Why did the Northern Hongshan Culture 6,000 years ago and the Southern Liangzhu Culture 5,000 years ago that are considered as the peaks in the development history of East Asian jade culture fail to spawn any culturally strong state but merely some local political power? An important reason is that neither of them has the economic pulling effect of long-distance trade and jade materials transportation. The jade materials supplied by local producers were self-sufficient. It is impossible to organize vast natural resources and social forces by overcoming geographical restrictions. The case is not the same with the ensuing Xia, Shang and Zhou dynasties. In order to overcome the inherent shortage of the supply of superior jade mines in the Central Plains, the early state rulers had a special liking for the beauty of the Western Regions jade, and they obtained as much jade as possible at the cost of huge manpower and material resources. Then there are the following jaw-dropping scenes as depicted in the ancient books:

It is hard to get jade. You need to cross three rivers and five lakes to reach Kunlun Mountains. If 1,000 people go there, only 100 of them can return. Among a hundred people who go, only ten of them can reach the destination (Shizi).

What is the ethnic group living in the Kunlun Mountains at that time? Wang Guowei, Xu Zhongshu and others thought they are Dayue people (written as "Yuzhi" or "Yushi" in ancient literature). Wang said in his book of 1952 The Study on the Residence of Yueshi People Migrating West to the Great Xia State: "The old residence of later Yueshi people may be located in northern China." Yizhou Book: Wanghui Part says "Yiyin said to superiors" Yushi people is right in north. The Story of Emperor Mu says "reach the Yuzhi place in Yihai year”. Yuzhi is also called Yushi and this group of people lived in the northwest of Yanmen, east of Yellow River, which agrees with the statement of Yiyin. These two books are the works of the Warring States period, so Yueshi people should be right in northern China at that time. The Book of History: The Story of Dawanlie says, "Yue people live between Dunhuang and Qilian range,” a story of the Qin and Han period. Guanzi: Guoxu Chapter says: Jade stems from the Yu people. Dishu Chapter says: Jade starts from Niushibian Mount. Qingzhongyi Chapter says, "The metals are produced in the right wing of the Han territory, gemstones are produced in the wild place with red gloss, and jade are produced in Pangshan where Yu people lives. All of these places are some 700 to 800 li from the Zhou state." Yu place is all considered as the origin of jade. Yuning annotated, the chapters of Guanzi: Qingzhong were written during Emperors Wen and Jing of the Han dynasty, a time when the Yue people had gone to Dunhuang and Qilian range, living between Qiemo and Yudian in the west, thereby saying "jade is produced by the Yu people."

Shizi and Guanzi are the pre-Qin classics that traditional Confucian classics do not stress. Now it is very important to see the information about the West-East Jade Transmission. Especially in the Hetao area bordered by Inner Mongolia and Shaanxi is not much of a concern for those scholars who studied the origin of civilization in the past. At present, they have discovered 4 million square meters of prehistoric ancient city, claiming to be China's largest prehistoric stone city. What is worth attention is that among the stone walls built 
4,000 years ago, there were also jade articles. Archaeologists estimate that as many as 4,000 pieces of ancient jade that were collected and sold to the cultural relics market at home and abroad at the Shenmu Dendrobium site! This figure is double the total number of jade articles unearthed in the Shang Dynasty. There is no scientific data yet. What is the source of the materials used in Shijie jade? Judging from the experience, it seems that the Qilian jade in the Qinghai area of Gansu was dominant, and its spreading path was likely to follow the trend of the upper reaches of the Yellow River. The prehistoric jade culture of the northwest, which is equivalent to the Shimao Age jade culture, is Qijia culture. Some jade materials of the Qijia culture are from Xinjiang Hetian. According to the "Hebei Kunlun" in the ancient books such as The Classic of Mountains and Seas, the saying of "Jade out of Kunlun Mountains" believed by the Central Plains people is a complete overlap of the jade spreading path and the Yellow River orientation. Judging from the sayings of Yu Gong and The Book of History: Liuhou Families such as "the Yellow River and the Wei River as the worldly waterways", the Yellow River could serve as a waterway capable of transporting materials in ancient times.

The Classic of Mountains and Seas: Inner East says: Inner East: Mount Kunlun lies northwest of the capital of the mortal world under the rule of the God of Heaven... On each side of the mountain are nine wells and their railings are made of jade. This is the place where a hundred gods reside. The Chishui River flows out of the southeast corner of Mount Kunlun and runs to the northeast...into a mountain of jade.

Huainanzi: Suixing Doctrine says, "The stones build up as the river flows.” Gao You annotated, "The river emanates from the Kunlun Mountains, and flows over the middle land measuring some 3,000 li. The Great Yu made the river unobstructed and that is why there are cumulated stones.”

The Hexi Corridor is the fortress of the jade road. There are place names such as "Yumen" on the way. As early as 2,000 years ago, before Zhang Qian made his way through the Western Regions, this dangerous road had already been opened, for the purpose of importing Hetian jade. In the pre-Qin literature, only a very few people arrived at the Kunlun Mountains. For example, The Classic of Mountains and Seas says, only Yi can ascend the mountain rock, and what is this hero going to the Kunlun Mountains for? For elixir. If you ask again: What constitutes the elixir governed by the Xi Wangmu (Queen Mother of the West)? The answer is Hetian jade- the sacred object that the Chinese has worshiped for thousands of years. 